Running Head: Contrast effect in spatial context

\title{
Contrast effect in spatial context: Robustness and practical significance
}

\author{
Christophe Blaison ${ }^{\mathrm{a}}$ \\ Marie-Pierre Fayant ${ }^{\mathrm{b}}$ \\ Ursula Hess $^{\mathrm{a}}$ \\ ${ }^{a}$ Humboldt-Universität zu Berlin, Berlin, Germany \\ ${ }^{\mathrm{b}}$ Université Paris Descartes, Paris, France \\ in press, Journal of Experimental Psychology: Applied
}

CAmerican Psychological Association, 2017. This paper is not the copy of record and may not exactly replicate the authoritative document published in the APA journal. Please do not copy or cite without author's permission. The final article is available, upon publication, at: XXXXXX

\section{Author Note}

Christophe Blaison, Department of Psychology, Humboldt-Universität zu Berlin. Marie-Pierre Fayant, Department of Psychology, Université Paris Descartes. Ursula Hess, Department of Psychology, Humboldt-Universität zu Berlin.

Correspondence concerning this article should be addressed to Christophe Blaison, Department of Psychology, Humboldt-Universität zu Berlin, Rudower Chaussee 18, 12489 Berlin Adlershof, Germany.

Email: christophe.blaison@hu-berlin.de 


\begin{abstract}
Contrary to lay conceptions, unattractive locations can under certain circumstances increase the perceived value of neighboring areas. This phenomenon is akin to a contrast effect. However, extant research on this type of contrast suffers from two limitations. First, the use of repeated measures may inflate the likelihood of observing a contrast effect. Second, there is a lack of meaningful comparisons for gauging the size of the effect. We designed three experiments to address these issues. In each, we assessed how much participants valued places located increasingly far from an unsafe housing block. Participants either rated several target locations or just a single one at a time. We also assessed whether the positiveness of the contrast effect due to the unsafe housing block would be able to compete with the positive effect of a nearby park. The results replicate past findings of a contrast effect in spatial context; they show that the effect generalizes to a different design; and they demonstrate that a contrast effect due to an unattractive location can indeed be as "beneficial" for some neighboring areas as the effect of a genuinely attractive location.

Word count abstract: 186
\end{abstract}

Keywords: Spatial context, place evaluation, assimilation and contrast, evaluative information integration, experimental design.

\title{
Public Significance Statement
}

The present study shows that an unattractive location, like an unsafe housing block, boosts the attractiveness of the farther surroundings by contrast. This boost can equal the positive effect of a genuinely positive location, like a park. This perception bias may be of interest to realestate businesses and buyers because it influences the value accorded to property, and to urban planners because it helps to explain how residential segregation develops. 
Contrast effect in spatial context: Robustness and practical significance If you were looking for a new home you would probably, like nine out of ten Americans (National Association of Realtors, 2016), call up an online real-estate website. These sites typically display home offers from a satellite view (e.g., Zillow.com, Realtor.com, or Trulia.com). While browsing the area, your feelings about the offers would inform your assessment of the various homes (Peters, Västfjäll, Gärling, \& Slovic, 2006; Slovic, Finucane, \& Peters, 2007; Wyer, Clore, \& Isbell, 1999). This assessment will depend in part on the intrinsic characteristics of the home (e.g., its architecture, the presence of a garden, etc.), but also on your impression of surrounding locations. For example, you may feel uneasy about living close to a railroad or an unsafe looking housing block because you believe that such locations taint the surroundings. Only recently has some research systematically investigated this notion (Blaison, Gollwitzer, \& Hess, 2017; Blaison \& Hess, 2016). One of its most interesting results is that, contrary to lay beliefs, unattractive locations - or negative "hotspots" - can in certain circumstances increase the perceived value of neighboring areas. The present research asks whether this effect, which is akin to a contrast effect in spatial context (Blaison \& Hess, 2016), is robust and significant enough to be considered in future research.

\section{The Contrast Effect in Spatial Context}

Context influences human judgments (Suls \& Wheeler, 2000, 2007). Judgment moves either toward the contextual information - i.e., an assimilation effect - or in the opposite direction - i.e., a contrast effect. According to the inclusion/exclusion model of assimilation and contrast (IEM; Bless \& Schwarz, 2010; Schwarz \& Bless, 1992, 2007), the direction of the context effect depends on whether the contextual information is included into, or excluded from, the representation of the target. Assimilation occurs when it is included in the target representation. By contrast when context information is excluded it may serve as an external standard of comparison and elicits contrast. For example, when people think about politicians 
in general, Nixon makes politicians appear less trustworthy because Nixon is a politician (inclusion thus assimilation). However, when comparing Nixon with Clinton, Clinton appears more trustworthy because Nixon is not Clinton (exclusion thus contrast).

One important factor underlying inclusion vs. exclusion is the extent of similarity, or feature overlap, between contextual information and target (Bless \& Schwarz, 2010). Less feature overlap reduces inclusion, and in turn favors contrast over assimilation. For example, highly attractive individuals make us feel more attractive when we share a similar attribute with them, but they make us feel less attractive when we don't (Brown, Novick, Lord, \& Richards, 1992). In spatial context, people associate similarity, or feature overlap, with proximity (Lakoff \& Johnson, 1999; Wertheimer, 1923). People perceive closer documents (Montello, Fabrikant, Ruocco, \& Middleton, 2003), closer abstract nouns (Casanto, 2008), and the color of closer geometrical figures (Boot \& Pecher, 2010) as more similar. Interestingly, decreasing physical distance to an individual fosters self-evaluative assimilation, while increasing distance fosters contrast (Fayant, Muller, Nurra, Alexopoulos, \& Palluel-Germain, 2011). Therefore, proximity between locations favors assimilation such that a negative hotspot, for example, decreases the attractiveness of nearby locations. The second part of the implication, however, is that distance between locations should foster contrast such that the negative hotspot increases attractiveness of distant locations.

Evidence for this notion stems from Blaison and Hess (2016) who presented bird's-eye views of neighborhoods and asked participants to rate several target locations situated at increasing distance from a negative hotspot (e.g., an unsafe housing block). As expected, the results show that the closest target locations were rated significantly less attractive than in a control condition without negative hotspot. This result concords with an assimilation effect. ${ }^{1}$

\footnotetext{
${ }^{1}$ Blaison and Hess (2016) called this result an "influence effect" to acknowledge that in real settings the negative locations might affect the neighborhood for real (e.g., criminal activity that originates in an unsafe housing block spreads to neighboring places) and not just affect the evaluation of such settings. As this differentiation is unimportant in the present research we will stick with the more conventional "assimilation" term.
} 
Moreover distant target locations were rated significantly more attractive than in the control condition, which is compatible with the contrast effect predicted by the theory. By the same token, assimilation and contrast emerge for positive hotspots (e.g., a park, the home of a liked celebrity; Blaison, Gebauer, Gollwitzer, Schott, Kastendieck, \& Hess, 2016; Blaison et al., 2017), albeit in the reverse direction.

Importantly, these assimilation and contrast effects were not due to a communication bias due to the mapping of scale categories on the range of presented stimuli (Campbell, Lewis, \& Hunt, 1958; Wedell, Hicklin, \& Smarandescu, 2007). Specifically, in one study, participants reported how much rent in dollars they would be ready to pay to live in target locations at increasing distance from a negative hotspot (i.e., a landfill or a house where a murder occurred in the past, Blaison \& Hess, 2016, Study 3). This open-ended response did not allow for a communication bias due to scale use, yet both an influence and a contrast effect emerged. On average, participants were ready to pay $\$ 83$ more rent (approx. $16 \%$ ) for an apartment that is further away from the negative hotspot than for a similar apartment in a control condition without any negative hotspot.

\section{Robustness and Practical Significance of the Contrast Effect in Spatial Context}

The previous findings support the claim that negative hotspots can have "beneficial" effects on parts of the environment (contrast effect). However, to assert such a conclusion requires demonstrating the replicability, the generality, and the practical significance of the contrast effect in spatial context. The present research aims to achieve this by replicating and extending the previous evidence in two ways.

First, the previous evidence relies on a design where the same participants rate each of the locations within a given neighborhood. This design allows for the possibility of demand effects due to the relative transparency of the manipulation (cf. Kahneman \& Frederick, 2005; Tversky \& Kahneman, 1983; but see Lambdin \& Shaffer, 2009). Thus, participants in Blaison and Hess (2016) might have inferred that the authors expected an increase in location 
attractiveness with increasing distance to the negative hotspot. As a result, the participants in the negative hotspot condition may have exaggerated the attractiveness increase on purpose, which artificially produced a contrast effect.

A further concern is that a repeated-measures design incites participants to explicitly compare each stimulus to one another. This systematic comparison process accentuates the perceived similarities and differences between stimuli, which would facilitate the emergence of assimilation and contrast (Bless \& Schwarz, 1992). In addition, emphasizing the comparison between the presented locations may inhibit the generation of counterfactual spatial contexts. In other circumstances, for example, participants could think about locations situated even farther away from the hotspot than any of the presented ones. Yet we know that larger spatial contexts make contrast effects emerge further into the distance (Blaison \& Hess, 2016). Thus, by focusing participants' attention on the presented spatial context and by emphasizing similarity and differences between elements, within-subjects designs may inflate the size of contrast effects.

To address these issues we modified the design such that each participant rated only one of the locations situated at increasing distance from the hotspot. This change also extends the ecological validity of the results. While the within-subjects manipulation of distance mimics the case where people consider multiple target locations simultaneously (e.g., multiple property offers presented on a map), the between-subjects manipulation mimics the case where only one target location is explicitly considered (e.g., only one property is of interest).

We further changed the design to provide evidence for the practical significance of the contrast effect. Specifically, we assessed the size of the "benefit" provided by a distant negative hotspot in relation to the size of the benefit provided by a nearby positive hotspot in this case an urban park (positive assimilation effect).

We conducted three experiments. Experiment 1a is a close replication of Blaison and Hess's (2016) Study 3 with an unsafe housing block instead of a landfill or a house where a 
murder occurred in the past. Experiment $1 \mathrm{~b}$ is similar to Experiment 1a with the major difference that the distance manipulation is not within-subjects but between-subjects, as described above. Experiment 2 is an extended replication of Experiment $1 \mathrm{~b}$ using a betweensubjects design to compare the size of the "benefit" provided by a distant unsafe housing project to the size of the benefit provided by a nearby urban park. We will report Experiment $1 \mathrm{a}$ and $1 \mathrm{~b}$ together, then Experiment 2.

\section{Experiment 1a and 1b}

In Experiments 1a and 1b, we asked participants to estimate how much rent (in dollars) they would be willing to pay for apartments located at an increasing distance from an unsafe housing block. We used an unsafe housing block because a) it elicited strong and reliable contrast effects in previous research (Blaison et al., 2016; Blaison et al., 2017; Blaison \& Hess, 2016); b) it is a negative hotspot that is ubiquitous in most cities; and c) safety from crime is a concern for most people. We used an objective criterion such as rent rather than a Likert-scale measuring subjective pleasantness to avoid alternative interpretations in terms of shift of meaning of the scale anchors between the conditions (Birbaum, 1999; see also Biernat \& Manis, 2007; Biernat, Vescio, \& Manis, 1998) or in terms of communication bias due to the mapping of the response scale on the range of stimuli (Wedell, Hicklin, \& Smarandescu, 2007). Furthermore, money is widely used as a proxy for utility (i.e., the value or amount of pleasure provided by a good) in the psychology of judgment and decision making (e.g., Buechel \& Morewedge, 2014) making it directly relevant to the question at hand.

Participants in the control condition were shown the same neighborhood but without the unsafe housing block. Experiment 1a employed a mixed design where each group of participants in the negative hotspot and in the control condition rated each of four target locations. Experiment $1 \mathrm{~b}$ employed a between-subjects design with the same negative hotspot and control conditions as in Experiment 1a but each participant rated only one of the four target locations. In both Experiment 1a and 1b, we expected a linear increase of rent with 
increasing distance to the negative hotspot and no such increase in the control condition.

Furthermore, we expected an assimilation effect such that the rent for the closest locations is lower than in the control condition as well as a contrast effect such that the rent for the farthest locations is higher than in the control condition.

\section{Methods}

Participants and Design. We conducted a power analysis based on the standard deviation of the rent variable obtained for the most distant apartment in Blaison and Hess (2016, Study 3). To detect a difference of $\$ 100$ between the negative hotspot and the control condition in a between-subjects design with a power ranging between .80 and $.90,50$ to 70 participants per condition are required (GPower; Faul, Erdfelder, Lang, \& Buchner, 2007). Therefore we recruited approximately 60 participants per condition for both Experiment 1a and 1b. A total of 625 participants were recruited online via Amazon's Mechanical Turk. ${ }^{2}$ To ensure high quality data, we selected workers who had accomplished a minimum of 100 Mechanical Turk tasks (i.e., "hits") with a requester satisfaction rate of $95 \% .{ }^{3}$ We excluded ten participants because they participated more than once in the hits. In addition, five participants were excluded from further analyses because they indicated rents higher than three standard deviations from the mean that were clearly detached from the rest of the sample. Thus, the final sample included 610 participants, all U.S. residents. In Experiment 1a $\left(N=117 ; 59\right.$ women; $M_{\text {age }}=35$ years, $\left.S D=11\right)$, participants were randomly assigned to a 2 (negative hotspot: unsafe housing block, none) $\times 4$ (distance)

mixed design with negative hotspot as between-subjects factor and distance as within-subjects factor. In Experiment $1 \mathrm{~b}\left(N=493 ; 240\right.$ women; $M_{\text {age }}=34.5$ years, $\left.S D=11\right)$, participants

\footnotetext{
${ }^{2}$ Amazon's Mechanical Turk is an online source of high quality data (Behrend, Sharek, Meade, \& Wiebe, 2011; Berinsky et al., 2012; Germine, Nakayama, Duchaine, Chabris, Chatterjee, \& Wilmer, 2012; Mason \& Suri, 2012; Paolacci, Chandler, \& Ipeirotis, 2010; but see Crump, McDonnell, \& Gureckis, 2013). It allows the collection of large samples that are more diverse than student panels (Berinsky, Huber, \& Lenz, 2012). Several experiments show that Mturkers are at least as much attentive and honest than student panels (Behrend, Sharek, Meade, \& Wiebe, 2011; Hauser \& Schwarz, 2015; Paolacci et al., 2010).

${ }^{3}$ A similar selection rule was used in all experiments. We made sure that no worker participated more than once in the experiments.
} 
were randomly assigned to a 2 (negative hotspot: unsafe housing block, none) $\times 4$ (distance) between-subjects design.

Material and Procedure. Participants saw a satellite photo of a neighborhood as shown in Figure 1 where a white arrow indicated the location of the apartment to assess. The neighborhood was a patchwork of existing housing blocks from different locations.

The same neighborhood was used in all conditions except that in the negative hotspot condition an unsafe housing block was positioned at one of the ends of the neighborhood (position to the left or right was counterbalanced across subjects). To render the hotspot unsafe in the eyes of the participants, we added the symbols of a gun and a syringe and informed the participants in writing that the symbols convey the notion that "gang activity and drug traffic pervade the housing block." In the control condition, the unsafe housing block was replaced with a neutral housing block (see Figure 1).
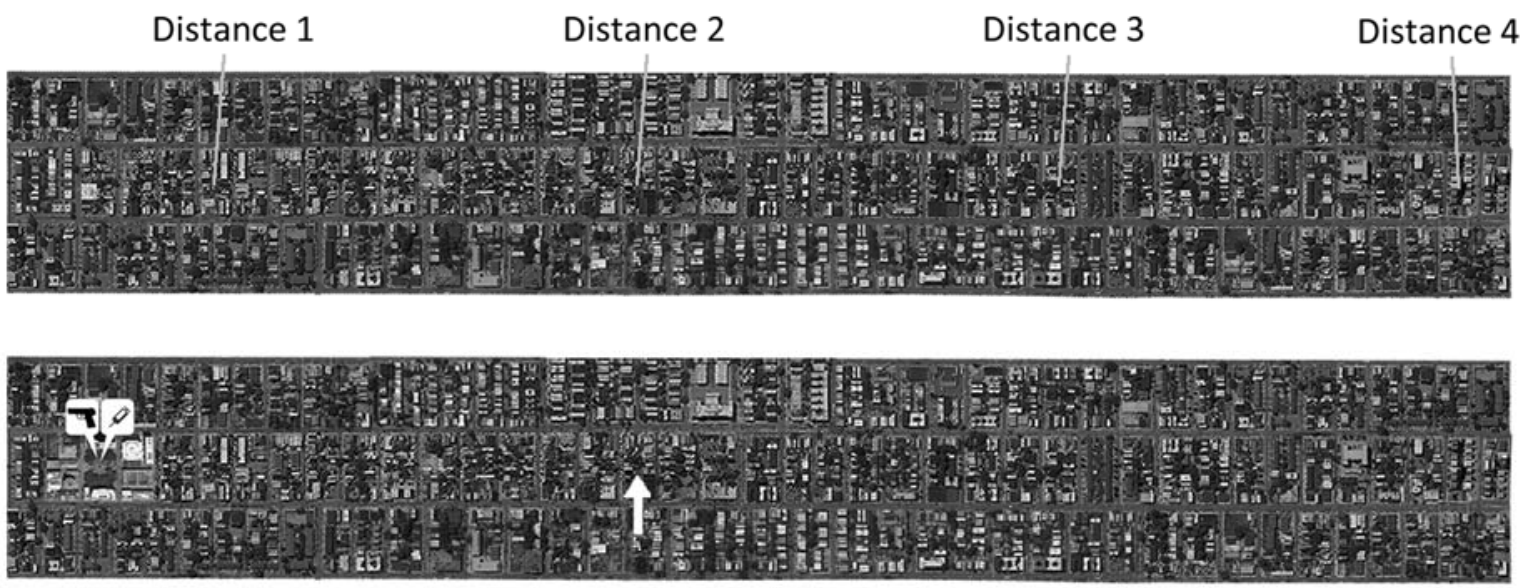

Figure 1. Example of stimuli used in the control and negative hotspot conditions (Experiments 1a and 1b). The upper panel represents to the control condition while the lower one represents the negative hotspot condition. The distances are indicated for information purpose only. The white arrow indicated to the participants which block to rate.

Participants were informed that the rent for a $750 \mathrm{Sq}$ Ft apartment with 1 bedroom and 1 bath was a minimum of $\$ 300$ in this city. In Experiment 1a participants were then asked to estimate how much rent they would be willing to pay for such an apartment at four different locations (see Distance 1 to 4 in Figure 1). The location presentation order was in a different 
random order for each participant. The instructions in Experiment $1 \mathrm{~b}$ were identical, except that the participants were asked to rate only one out of the four target locations.

\section{Results}

In the following analysis, we used the Greenhouse-Geisser correction and rounded the corrected degrees of freedom to the nearest integer when the sphericity assumption was violated (Mauchly test, $p<.001$ ).

Experiment 1a. We conducted a 2 (negative hotspot: unsafe housing block, none) x 4 (distance) mixed ANOVA on the rent the participants were willing to pay. The results show a significant main effect of distance, $F(2,268)=50.16, p<.001, \eta^{2}{ }_{p}=.30$, and a significant distance by negative hotspot interaction effect, $F(2,268)=66.89, p<.001, \eta^{2}=.37$. To test the linear increase of rent with increasing distance to the negative hotspot, we decomposed the distance effect in one linear contrast and the two orthogonal quadratic and cubic contrasts. The linear increase of rent was stronger in the negative hotspot than in the control condition, $t(115)=10.89, p<.001, \eta^{2} p=0.51$. Simple effects analyses show that rent increased linearly in the negative hotspot condition, $t(115)=14.04, p<.001, \eta^{2}{ }_{p}=0.63$, whereas it did not in the control condition, $t(115)=1.10, p=.27, \eta^{2}{ }_{p}=0.01$. The quadratic and cubic contrasts were both non-significant, $p \mathrm{~s}>.54$.

As expected, there was an assimilation effect at Distance 1 and 2 such that the rent was lower in the negative hotspot condition than in the control condition. For Distance 1: $M_{\text {difference }}$ $=-164.2$, CI $[119,209.4], t(115)=7.19, p<.001, \eta^{2}=0.31$; for Distance $2: M_{\text {difference }}=-$ 60.2, CI $[3.6,116.8], t(115)=2.11, p<.001, \eta^{2} \mathrm{p}=0.04$. There was also evidence for a contrast effect at Distance 4 where the rent was higher in the negative hotspot condition than in the control condition: $M_{\text {difference }}=162.7$, CI $[90.1,235.3], t(115)=4.44, p<.001, \eta^{2} \mathrm{p}=$ 0.15 . 
Experiment 1b. We conducted a 2 (negative hotspot: unsafe housing block, none) x 4 (distance) ANOVA. Again, significant main effects of distance, $F(3,485)=12.54, p<.001$, $\eta^{2}{ }^{2}=.07$, and of negative hotspot, $F(1,485)=11.95, p=.001, \eta^{2}=.02$, emerged, which were qualified by the distance $\mathrm{x}$ negative hotspot interaction, $F(3,485)=10.72, p<.001, \eta^{2} \mathrm{p}$ $=.06$ (see Figure 2). Again, the linear increase of rent was stronger in the negative hotspot than in the control condition, $t(485)=5.17, p<.001, \eta^{2} \mathrm{p}=0.05$. Simple effects analyses showed that rent increased linearly in the negative hotspot condition, $t(485)=7.73, p<.001$, $\eta^{2} \mathrm{p}=0.11$, whereas it did not in the control condition, $t(485)=0.49, p=.62, \eta^{2} \mathrm{p}=0$. The quadratic contrast analysis indicated a larger quadratic trend (inverted U-shape) in the control than in the negative hotspot condition, $t(485)=0.49, p=.62, \eta^{2} \mathrm{p}=0$, whereas the cubic contrasts were not significant, $p \mathrm{~s}>.12$.

There was an assimilation effect at Distance 1 to 3 such that the rent in the negative hotspot condition was lower than in the control condition. For Distance 1: $M_{\text {difference }}=-135.6$, CI $[72.9,198.3], t(485)=4.24, p<.001, \eta_{p}^{2}=0.04$. For Distance $2: M_{\text {difference }}=-111.1, \mathrm{CI}$ $[48.63,173.55], t(485)=3.49, p<.001, \eta^{2} \mathrm{p}=0.02$. For Distance $3: M_{\text {difference }}=-67.7$, CI $[5.2$, 130.2], $t(485)=2.13, p=.03, \eta^{2} \mathrm{p}=0.01$. There was also a contrast effect at Distance 4 where again the rent in the hotspot condition was significantly higher than the rent in the control condition: $M_{\text {difference }}=94.7$, CI $[32.7,156.7], t(485)=3.00, p=.003, \eta^{2} \mathrm{p}=0.02$.

\section{Discussion.}

The goal of Experiment $1 \mathrm{a}$ and $1 \mathrm{~b}$ was to provide further evidence for the robustness and the generalizability of the contrast effect in spatial context observed in previous studies (Blaison and Hess, 2016). The contrast effect elicited by the distant unsafe housing block emerged when each participant assessed every target locations as well as when they assessed only one location. These results support the view that the contrast effect in spatial context is a robust phenomenon that replicates well across different designs. Yet, the contrast effect was 


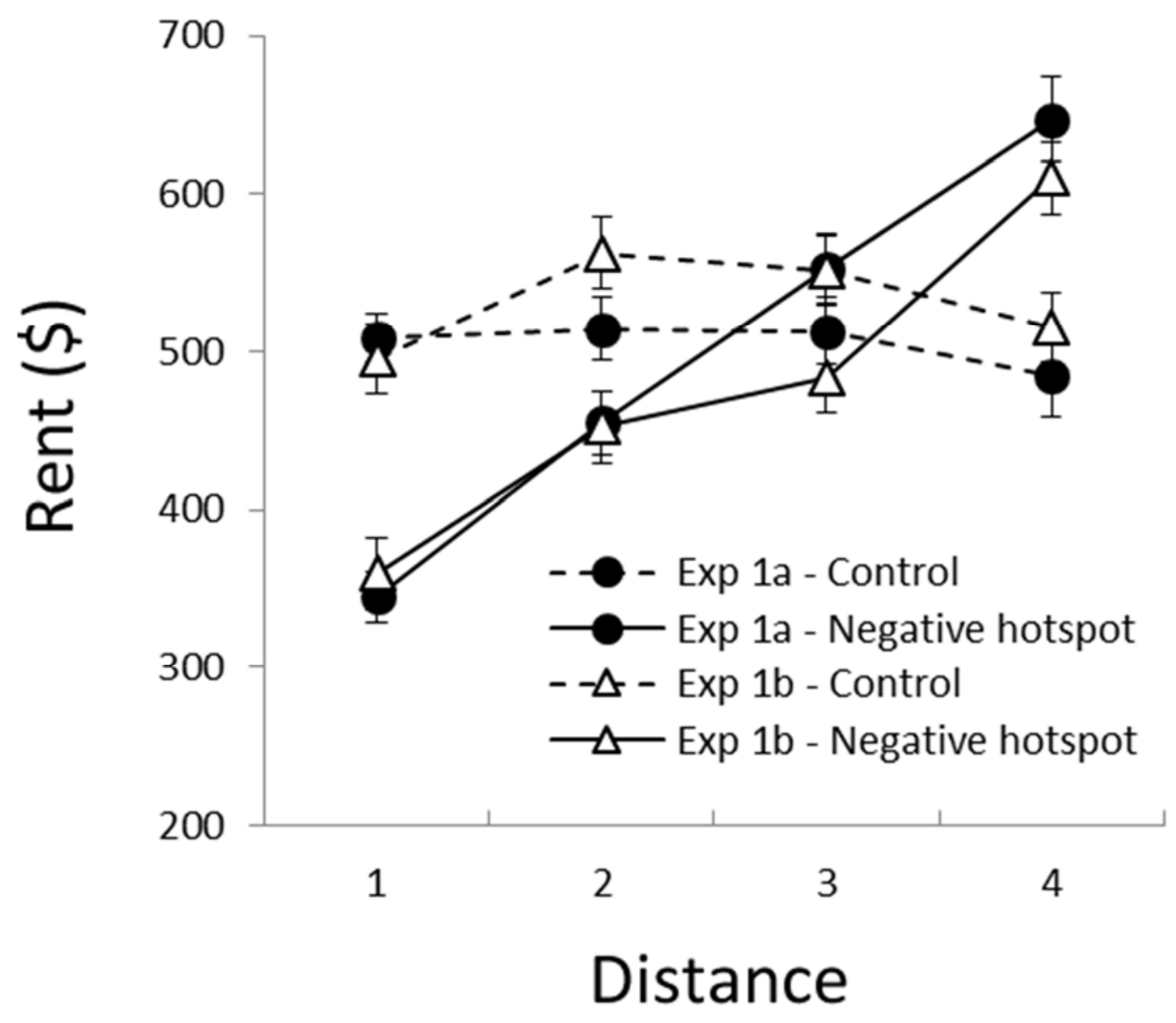

Figure 2. Rent that the participants were ready to pay as a function of target location and design (Experiment 1a and 1b). Exp 1a = within-subjects manipulation of distance; Exp 1b $=$ between-subjects manipulation of distance. The error bars represent standard errors of the mean.

somewhat stronger when the distance was manipulated within-subjects rather than betweensubjects. Compared to the control condition, the unsafe housing block increased the average value of distant apartments by $\$ 160$ / month for Experiment 1a but only by about $\$ 95$ / month for Experiment 1b, suggesting that demand effects, systematic comparison processes or exclusive use of the prescribed spatial context may have boosted the contrast effect in the within-subjects design.

Even though, both sums represent non-trivial amounts for apartments of this size (33.60\% and $15.53 \%$ increase in rent respectively). The practical relevance of this increase should to be put in relation to the effect of an intrinsically positive hotspot like an urban park.

\section{Experiment 2}


Experiment 2 assessed the "gain" due to a distant unsafe housing block in relation to the direct benefit provided by a nearby urban park. We chose a park because a) it is ubiquitous in most cities; b) it elicits reliable assimilation and contrast effects (Blaison et al., 2016; Blaison et al., 2017); c) it is rated roughly as intensely positive than an unsafe housing block is rated intensely negative (Blaison et al., 2016; Blaison et al., 2017, Study 1). Participants again indicated the rent they would be willing to pay for an apartment that was either a) located far away from an unsafe housing block; b) located close to an urban park; c) located close to an urban park and far away from an unsafe housing block; or d) located in a neighborhood devoid of any hotspots (control). As in Experiment $1 \mathrm{~b}$ we expected higher rents in the distant unsafe housing block condition than in the control condition. The predictions regarding the nearby urban park and the nearby urban park + distant unsafe housing block conditions were less straightforward even though we generally expected higher rents than in the control condition. These two conditions enable us to explore whether the increase in value due to the contrast effect is lower than, as great as, or greater than the positive assimilation effect of an urban park, and whether the contrast and the assimilation effect are additive.

\section{Method}

Participants and Design. A total of 385 participants were recruited online via Amazon's Mechanical Turk. We increased the power of Experiment 2 compared to Experiment $1 \mathrm{a}$ and $1 \mathrm{~b}$ to detect smaller effects. We excluded nine participants because they participated more than once. In addition, four participants were excluded from further analyzes because they indicated rents three standard deviations above the mean that were clearly detached from the rest of the sample. Thus, the final sample included 373 participants (239 women, unknown one gender, all U.S. residents) with an average age of 36.4 years (SD = 11.9). We used a 4 (condition: negative hotspot, positive hotspot, negative + positive hotspot, no hotspot $=$ control) between-subjects design with the rent given at Distance 4 as dependent variable (see Figure 3). 
Distance 4
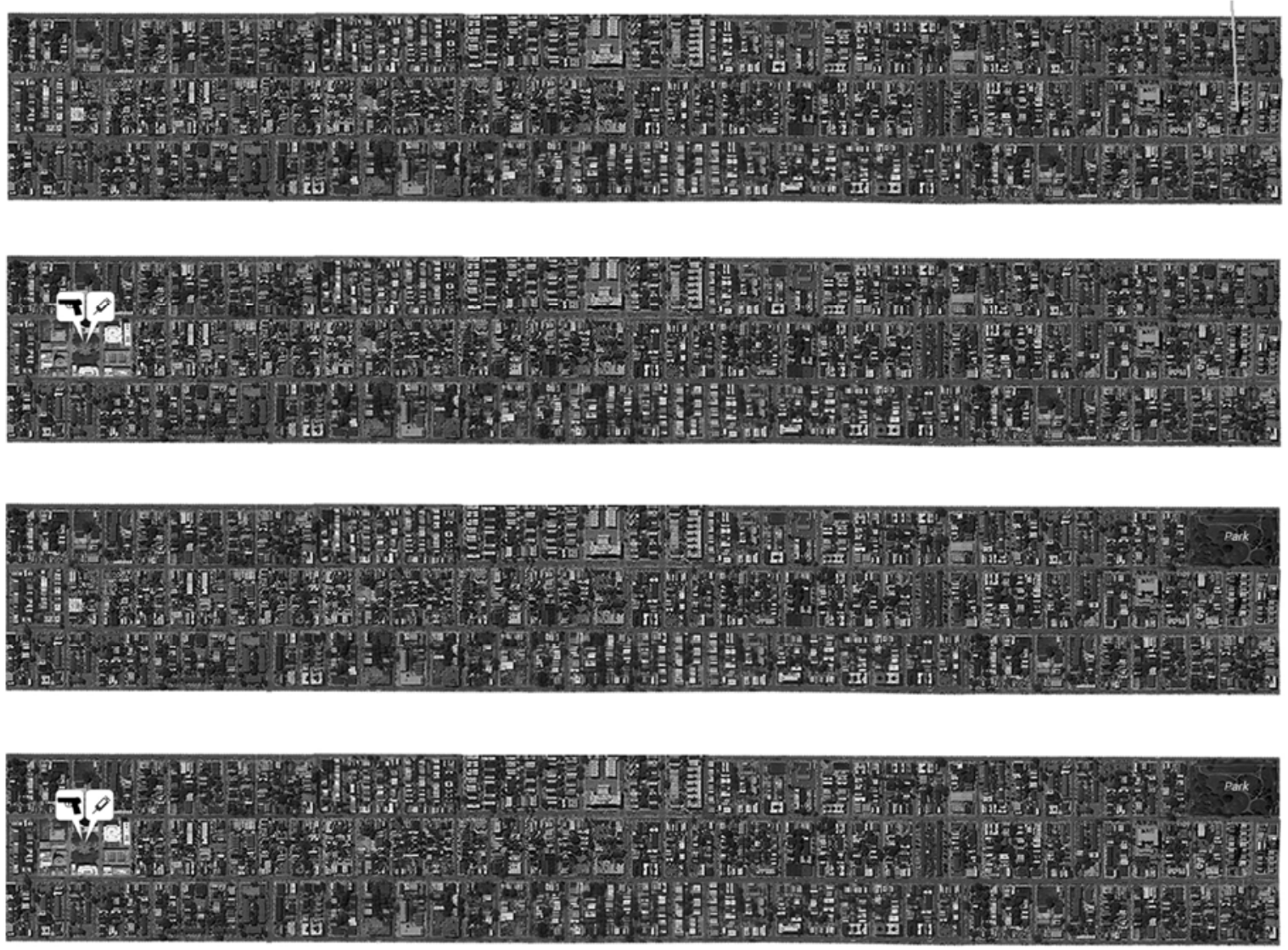

Figure 3. Example of stimuli used in the control, negative hotspot, positive hotspot, negative + positive hotspot conditions (top to bottom panel; Experiment 2). Distance 4 is indicated for information purpose only.

Material and Procedure. The neighborhoods used in the control and the negative hotspot conditions were the same as the ones used in Experiment 1a and 1b. In the positive hotspot condition the neighborhood contained an urban park in one of the top corners.

Previous research shows that parks increase the sales price of property in the surroundings (e.g., Anderson \& West, 2006) and that people judge the positive influence of a park as positive as they judge the negative influence of an unsafe housing block to be negative (Blaison et al., 2016). In the negative + positive hotspot condition, the neighborhood contained both an unsafe housing block and a park as depicted in Figure 3. The rest of the procedure was the same as Experiment $1 \mathrm{~b}$.

\section{Results and Discussion}


We conducted a 4 (condition: negative hotspot, positive hotspot, negative + positive hotspot, control) ANOVA on the indicated rent at distance 4. A main effect of condition emerged, $F(3,369)=3.12, p=.03, \eta^{2} \mathrm{p}=.03$ (see Figure 4). We decomposed this effect with the following series of orthogonal contrasts: $\mathrm{C} 1=$ control versus the other conditions; $\mathrm{C} 2=$ negative + positive hotspot versus negative hotspot and positive hotspot; $\mathrm{C} 3=$ negative hotspot versus positive hotspot. As predicted, C1 was significant, $t(369)=2.98, p=.003, \eta^{2} p$ $=.02$, with the rent in the control condition being lower than in the other conditions such that $M_{\text {difference }}=-65.6,95 \%$ CI $[22.4,108.8]$. C2 (combined versus negative and positive hotspots), $t(369)=0.62, p=.54$, and C3 (negative versus positive hotspot), $t(369)=0.92, p=.92$, did not emerge significantly. ${ }^{4}$ In addition, the combined effect of C2 and C3 was not significant (Judd, McClelland, \& Ryan, 2009), $t(369)=0.62, p=.53, \eta_{\mathrm{p}}^{2}=0$, which suggests that the mere presence of any hotspot accounts for the bulk of the rent variation at Distance 4 and that the variations between the hotspot conditions are negligible.

To assess the size of the benefit elicited by each hotspot condition, we estimated the effect of the hotspots compared to the control condition. On average, the distant negative hotspot increased the rent by $\$ 69.1,95 \%$ CI $[16.1,122.1], t(369)=2.57, p=0.01 ; \eta^{2} p=0.02$. This result replicates the contrast effect found in Study 1b. The nearby park increased the rent by $\$ 71.9,95 \% \mathrm{CI}[18.9,124.9], t(369)=2.67, p=0.008 ; \eta^{2}=0.02$. The combination of both increased the rent by $\$ 55.7,95 \%$ CI $[1.8,109.6], t(369)=2.03, p=0.04, \eta^{2} \mathrm{p}=0.02$.

In sum, we found that all hotspots conditions increased the rent at Distance 4 significantly (10\% to $13 \%$ rent increase on average). This increase was roughly similar across hotspot conditions. Of course, this does not mean that no difference exists; the smallest effect size our design could detect is a difference of $d=.40\left(\eta^{2} \mathrm{p}=0.04\right)$ [two tails, alpha $(\alpha)=.05$,

\footnotetext{
${ }^{4}$ There was a slight heterogeneity of variance between the conditions. The studentized deleted residuals revealed three participants who had a score superior to 3.50. Removing them from the analyses did not alter the conclusions; $\mathrm{C} 1$ was significant, $t(366)=2.79, p=.006, \eta_{\mathrm{p}}^{2}=.02$, whereas $\mathrm{C} 2$ and $\mathrm{C} 3$ were not, both $t \mathrm{~s}<.67$, both $p \mathrm{~s}>.50$.
} 


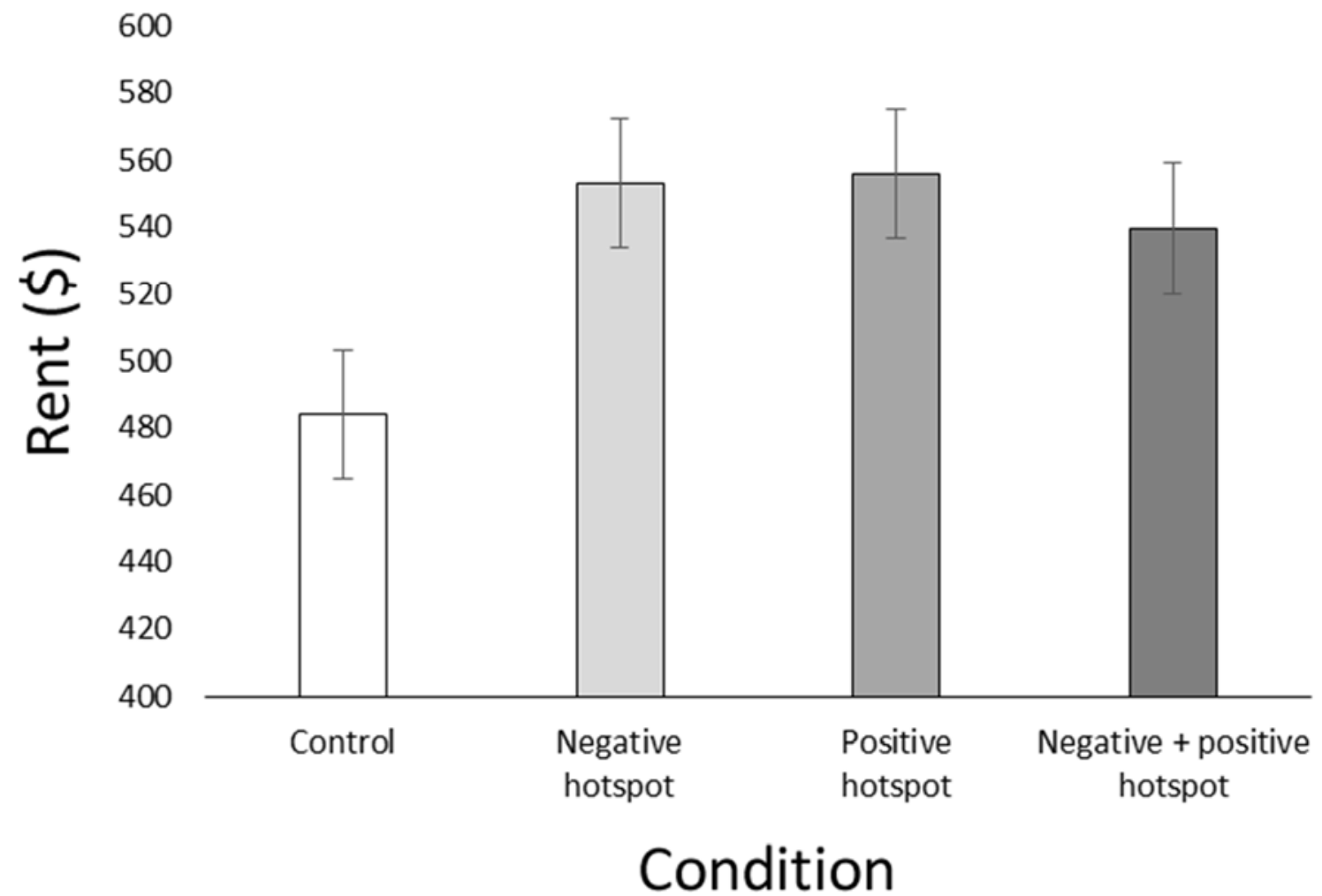

Figure 4. Rent (\$) that the participants would be willing to pay for an apartment located at Distance 4 as a function of the condition (Experiment 2). The error bars represent standard errors of the mean.

sample size of both conditions $n=94$, power $(1-\beta)=.80$; GPower; Faul et al., 2007], which is between a small $(d=.20)$ and a medium effect size $(d=.50)$ according to Cohen (1988).

Nevertheless, the descriptive tendency that we observed here - i.e., a difference of a few dollars - suggests that if a difference exists, it is rather small. Therefore, the present study, though underpowered for detecting small effects, suitably demonstrates the practical importance of contrast effects in spatial context. Importantly, Experiment 2 shows that the contrast effect elicited by an unsafe housing block is practically as positive as the effect due to a nearby park. This is particularly remarkable since an urban park is roughly perceived as intensely positive as an unsafe housing block is perceived as intensely negative (Blaison et al., 2016; Blaison et al., 2017).

The combined effect of the distant unsafe housing block and the nearby park was approximately equivalent to their effect taken in isolation. Even though the lack of power for 
detecting smaller effects also applies here, this result is intriguing. One might have expected an additive effect such that two positive effects (assimilation effect due to the park and contrast due to the unsafe housing block) bring more benefit than one single positive effect (assimilation effect due to nearby park or contrast effect due to the distant negative hotspot). One explanation is that whereas the park on its own was seen positively, the park in combination with the unsafe housing block was not. Adding the positive effect due to the distant unsafe housing block to an absence of positive effect from the nearby park would lead to the same result as the one due to an unsafe housing block on its own. Although unpublished results show that a park's evaluation even become negative when situated in direct proximity of an unsafe housing block (Blaison et al., 2016; Study 1), such a substantial devaluation is unlikely to have occurred in the present context. First, slightly increasing the distance between the park and the unsafe housing block suffices to switch the evaluation of the park back to positive (Blaison et al., 2016; Study 2). In our study, we adopted a much greater distance between the park and the unsafe housing block, which suggests that the park should have been at worst only slightly devalued. Second, positive contrast effects emerged at Distance 4, which is too far for negative assimilation effects, reinforcing the notion that a park located as far as Distance 4 is unlikely to be strongly devaluated.

If the park largely maintained its positivity, then the absence of significant difference between the combined and the isolated hotspots conditions is difficult to reconcile with an additive model of information integration. Had it been the case, Distance 4 would have looked significantly more attractive, which our design - with all its limitations - should have been able to detect.

It is, however, possible that participants averaged rather than added the outcomes of the contrast and the assimilation effect, as dominant models of information integration suggest (Anderson, 1981, 2014; Wyer \& Carlston, 1979). Averaging is supported by research that shows that when people form a global evaluation of person A who possesses two moderately 
and two extremely positive traits, or of person B who possesses only two extremely positive traits, they like person B more than person A (Anderson, 1965). Similarly, participants in the present research could have averaged the positive effect due to the distant housing project with the slightly reduced positive effect of the park. This process could also explain the descriptive tendency for Distance 4 to be rated less positively in the combined than in the isolated hotspot conditions (see Figure 4). In any case, future research should replicate this finding with a positive hotspot that is as intensely positive as a park while being less vulnerable to negative influence, like a celebrity home (Blaison et al., 2016; Blaison et al., 2017).

\section{General Discussion}

The present research assesses the robustness, the generalizability, and the practical significance of the contrast effect in spatial context shown in earlier work (Blaison et al., 2016; Blaison et al., 2017; Blaison and Hess, 2016). The results of three experiments replicate the contrast effect in spatial context found in previous research. They allow for generalization of the contrast effect from a within-subjects to a between-subjects design which is less susceptible to artifact. They also demonstrate the practical significance of the contrast effect in spatial context by showing that the "positive" effect of a negative hotspot can be as strong as that of an intrinsically positive hotspot. Overall, the present results corroborate and augment the accumulated evidence showing that the contrast effect in spatial context emerges for different negative and positive hotspots (Blaison et al., 2016; Blaison et al., 2017; Blaison \& Hess, 2016); that it emerges irrespective of the response format of the dependent variable (Likert scale or open-ended response with absolute criterion like rent; Blaison \& Hess, 2016; the present research) and, as demonstrated here, irrespective of the type of experimental design.

\section{Limitations}


Although the results are important for the literature on place evaluation, it is necessary to mention some limitations that require further research. First, the present results rest exclusively on bird's eye views. Bird's eye views make it easy to estimate distances (Thorndyke \& Hayes-Roth, 1982). In addition, such views are ubiquitous in a series of extremely popular services based on online maps, which lends clear real world relevance to the results. However, the question arises whether assimilation and contrast in spatial context would also emerge with a different mode of presentation. Previous research showed that assimilation emerges when describing an urban area verbally and when immersing participants in a first-person perspective of a neighborhood (Blaison \& Hess, 2016). Whether contrast also emerges in those conditions needs further confirmation but the present evidence suggests that it would. ${ }^{5}$ Overall the results suggest a common mechanism behind assimilation and contrast in spatial context.

A second limitation is the exclusive reliance on self-report. An important task for future research would be to demonstrate assimilation and contrast in spatial context with behavioral measures. For example, one could design an economic game where participants are asked to pay small amounts of real money for preferred locations. There is also a need to demonstrate assimilation and contrast in spatial context indirectly. One could present objects or individuals at locations situated at increasing distance from a hotspot. Provided the spatial context can influence judgment without explicit processing, then indirect measurement techniques should show that objects close to a hotspot took on evaluatively similar attributes (i.e., assimilation effect) whereas objects farther away took on contrastive ones (i.e., contrast effect).

\footnotetext{
${ }^{5}$ Experiment 1 from Blaison and Hess (2016) compared the increase in attractiveness with increasing distance to a negative hotspot in a bird's eye view as well as in a first-person perspective condition. The increase in attractiveness was similar; assimilation emerged in both conditions whereas contrast did not. One explanation for the absence of contrast could be that the surroundings were too small and too intrinsically attractive (Blaison \& Hess, 2016). Experiment 4 from Blaison and Hess (2016) described an urban area with a negative hotspot verbally. In the condition that was the most favorable to contrast, distant locations received pleasantness ratings well above the middle-point of the scale. This result supports the emergence of contrast in this presentation mode even though the absence of a control condition precludes any definitive conclusion.
} 
Finally, the finding that assimilation and contrast seems to have positive effects of similar magnitude is limited to the particular spatial context used in the present research. The use of a different negative hotspot, like a nuclear power plant, or the use of a different spatial arrangement could have led to different results. In the present spatial arrangement, the use of a nuclear power plant instead of the unsafe housing block could have led to a less intense contrast effect compared to the assimilation effect due to the park because the negative influence of a nuclear power plant extends farther (Blaison \& Hess, 2016). We tailored the spatial context that way in order to maximize the contrast and show that its effect can be that large. Further research should compare assimilation and contrast effects elicited by a larger variety of hotspots (positive and negative) to qualify and generalize the present results.

\section{Theoretical implications}

General implications for assimilation and contrast. The present research has interesting implications on how assimilation and contrast operate together. As far as we know, our research is the first to assess the outcome of a combination of positive assimilation and positive contrast effects elicited by several pieces of information of opposite valence. Past research studied how people integrate assimilation and contrast elicited by the same piece of information. Some of these studies showed that contrast wins over assimilation (Manis \& Paskewitz, 1984) whereas others showed that assimilation and contrast cancel each other out (Abele \& Gendolla, 1999; Wänke, Bless, \& Igou, 2001). For example, Study 3 from Wänke et al. (2001) suggests that an excellent toaster elicits contrast on a standard toaster whereas it elicits contrast as well as assimilation when their common brand is made salient. It seems as if the net effect of assimilation (positive effect) and contrast (negative effect) resulted in a standard toaster rating approximating the one in the control condition. Although the results support the assumption that assimilation and contrast neutralize each other, adding the positive assimilation and the negative contrast due to the excellent toaster gives the same neutral result as averaging these two effects. This study is thus ill conceived for drawing 
conclusions about how exactly people integrate simultaneous assimilation and contrast effects. By studying positive contrast and positive assimilation, our manipulation allows less ambiguous conclusions: an additive effect can be excluded because the combined effect of positive assimilation and positive contrast is not more positive than that of the effects taken in isolation.

A different avenue for future research could be to study the influence of individual differences in the weight accorded to positive assimilation compared to positive contrast. For instance, positive contrast (i.e., the positive effect due to a distant negative hotspot) could weigh more on the judgment of people high in prevention focus (i.e., people that value avoiding negative outcomes more than approaching positive ones; Higgins, 1998) whereas positive assimilation (i.e., a positive effect due to a close by positive hotspot) could weigh more on the judgment of people high in promotion focus (i.e., people that value approaching positive outcomes more than avoiding negative ones; Higgins, 1998). Finally, further research investigating the outcome of a fully crossed design involving hotspot valence (positive or negative), hotspot arrangement (combined or isolated presence) and distance to a target (close by or far away) could extend this set of consideration to any kind of scenario (e.g., simultaneous effect of negative assimilation and positive contrast).

Specific implications for the IEM. The current results suggest that contrast due to a negative information can be as intensely positive as assimilation due to a positive information that is roughly matched in evaluative intensity. Even if caution is required as we only assumed matched intensity based on previous research, this result is compatible with the IEM's claim that the size of assimilation and contrast effects depends on the intensity of the included or excluded contextual information (Bless \& Schwartz, 2010).

A different implication of the results concerns the IEM's notion of representativeness. The IEM states that the same piece of contextual information can elicit assimilation or contrast as a function of whether it serves to form the representation of the target or not. One 
important criterion for inclusion in the representation of the target is whether the contextual information is representative of the target, i.e., whether it is useful for inferring properties of the target. Representativeness greatly depends on the similarity or feature overlap between contextual information and target (Bless \& Schwarz, 2010). Based on range-frequency theory (Parducci, 1965), Blaison and Hess (2016) proposed that the representativeness of a piece of contextual information for the target depends on the larger context in which both are embedded. For example, an atypical politician (contextual information) would elicit assimilation for politicians in general (target) if the larger social context mostly consisted of people even less representative of the category "politicians" than he/she is (e.g., punk rockers) simply because he/she fits the politician prototype better compared to any other alternative in the accessible context. On the other hand, the atypical politician would elicit contrast if the social context mostly consisted of people who are more representative of the category "politicians" (e.g., established politicians). In addition to this notion, the present study suggests that the distribution of the other stimuli in the larger context could influence information representativeness as a Gestalt would influence the perception of its elements. Specifically, a Gestalt influences its elements irrespective of whether people attend to the whole as well as to each of its elements, or to only one single element. Likewise, participants' rating of a target location was similar whether they rated all locations that formed the larger context or not. These results are not unique, they resemble others showing that the distribution of stimuli in the larger context affects people's judgment even though these stimuli are not overtly rated (Parducci \& Weddell, 1986; Smith, Diener, \& Weddell, 1989). Future research should work towards integrating these notions into the IEM.

\section{Practical Implications}

The present results also have a series of practical implications. Irrespective of the number of target locations under a person's scrutiny, it is possible to influence where contrast effects emerge by manipulating the accessible spatial context. This insight should be of 
interest to any real-estate business; effective marketing should involve emphasizing a property's proximity to positive hotspots as well as distance to negative hotspots by selecting the appropriate spatial context. On the other side, clients - provided they are aware of the notions presented here - could use the same technique to their own advantage. To lead the negotiation on more favorable grounds, they could use variations of spatial context that emphasize the property's proximity to negative hotspots and/or distance to positive ones. During the negotiation with the seller, the client could introduce a larger spatial context (e.g., by expressing interest for a property located in a different neighborhood) to strengthen their negotiation position.

The results also have implications in other applied domains. Enhancing political leaders' ingroup-prototypicality is crucial in political communication because it gives more legitimacy to their leadership (Hogg, van Knippenberg, \& Rast, 2012). One way to achieve increased ingroup-prototypicality is to present their actions within a context where most other individuals are less prototypical than the leader. Expanding the prototypicality range of accessible political actors in the larger spatial context should lead to increased assimilation to the ingroup prototype for a given leader. The present results suggest that pointing to the flattering position of the political leader within the larger social context should suffice.

Finally, we would like to take an explicit stance against the claim that negative hotspots are acceptable because, after all, they benefit some areas in the surroundings (positive contrast effect). Negative hotspots polarize space affectively such that people are not only repelled by the area with the negative hotspot but also pulled towards the areas situated far away. As it is fueled by two complementary types of motivations (avoidance and approach), the effect is particularly strong. It may initiate a vicious cycle by eliciting less and less demand for the proximal area whereas distant areas elicit increasingly more demand, which increases social inequalities. Our results thus contribute to explain the processes behind residential segregation (e.g., Schelling, 1969). Familiar observers (e.g., inhabitants), however, 
may have less negative views with less affective polarization than unfamiliar observers (e.g., someone looking for a home in an unknown area) because the affective system reacts more to change than to continuing conditions (Helson, 1964; Kahneman, Diener, \& Schwarz, 1999). An interesting question for future research is whether a positive hotspot like a park would initiate the same type of vicious cycle as positive hotspots elicit positive assimilation nearby but negative contrast farther away (Blaison et al., 2017). If so, then the only way to avoid the deleterious effects of affective polarization of space may be to cover the urban landscape with a dense mesh of positive hotspots; this would prevent the emergence of any negative contrast effect and would in and of itself contribute to a more livable environment.

\section{Conclusion}

Contrast effects in spatial context are counterintuitive - why would negative hotspots increase the value of their environment? The present research contributes to ascertain that such a contrast effect is indeed robust, that it generalizes to different kinds of experimental designs, and that it has practical significance. Overall, the results add to the accumulated evidence that contrast effects in spatial context matter enough for us to care about them in future research as well as outside of the lab. 


\section{References}

Anderson, S. T., \& West, S. E. (2006). Open space, residential property values, and spatial context. Regional Science and Urban Economics, 36, 773-789.

Behrend, T. S., Sharek, D. S., Meade, A. W., \& Wiebe, E. N. (2011). The viability of crowdsourcing for survey research. Behavior Research Methods, 43, 800-813.

Berinsky, A. J., Huber, G. A., \& Lenz, G. S. (2012). Evaluating online labor markets for experimental research: Amazon.com's Mechanical Turk. Political Analysis, 20, 351368.

Birnbaum, M. H. (1999). How to show that $9>221$ : Collect judgments in a between-subjects design. Psychological Methods, 4, 243.

Blaison, C., Gebauer, J., Gollwitzer, M., Schott, F., Kastendieck, T., \& Hess, U. (2016). On the combined influence of attractive and unattractive locations. Manuscript submitted for publication.

Blaison, C., Gollwitzer, M., \& Hess, U. (2017). Effects of "hotspots" as a function of intrinsic neighborhood attractiveness. Journal of Environmental Psychology, 51, 57-69.

Blaison, C., \& Hess, U. (2016). Affective judgment in spatial context: How places derive affective meaning from the surroundings. Journal of Environmental Psychology, 47, 5365.

Bless, H., \& Schwarz, N. (2010). Mental construal and the emergence of assimilation and contrast effects: The inclusion/exclusion model. In M. P. Zanna (Ed.), Advances in experimental social psychology (Vol. 42, pp. 319-373). San Diego, CA: Elsevier Academic Press.

Boot, I., \& Pecher, D. (2010). Similarity is closeness: Metaphorical mapping in a conceptual task. The Quarterly Journal of Experimental Psychology, 63, 942-954. 
Brown, J. D., Novick, N. J., Lord, K. A., \& Richards, J. M. (1992). When Gulliver travels: Social context, psychological closeness, and self-appraisals. Journal of Personality and Social Psychology, 62, 717.

Buechel, E. C., \& Morewedge, C. K. (2014). The (relative and absolute) subjective value of money. In The psychological science of money (pp. 93-120). Springer New York.

Campbell, D. T., Lewis, N. A., \& Hunt, W. A. (1958). Context effects with judgmental language that is absolute, extensive, and extra-experimentally anchored. Journal of Experimental Psychology, 55, 220.

Casanto, D. (2008). Similarity and proximity: When does close in space mean close in mind? Memory \& Cognition, 36, 1047-1056.

Cook, T. D., \& Campbell, D. T. (1979). Quasi-experimentation. Design and analysis for field settings. Boston: Houghton Mifflin.

Crump, M. J., McDonnell, J. V., \& Gureckis, T. M. (2013). Evaluating Amazon's Mechanical Turk as a tool for experimental behavioral research. PloS one, 8, e57410.

Fayant, M. P., Muller, D., Nurra, C., Alexopoulos, T., \& Palluel-Germain, R. (2011). Moving forward is not only a metaphor: Approach and avoidance lead to self-evaluative assimilation and contrast. Journal of Experimental Social Psychology, 47, 241-245.

Germine L., Nakayama K., Duchaine B. C., Chabris C. F., Chatterjee G., \& Wilmer J. B. (2012). Is the web as good as the lab? Comparable performance from web and lab in cognitive/perceptual experiments. Psychonomic Bulletin Review, 19, 847-857.

Greenwald, A. G. (1976). Within-subjects designs: To use or not to use? Psychological Bulletin, 83, 314.

Hauser, D. J. \& Schwarz, N. (2016). Attentive Turkers: MTurk participants perform better on online attention checks than subject pool participants. Behavior Research Methods, 48 , 400-407. 
Helson, H. (1964). Adaptation level theory: An experimental and systematic approach to behavior. New York, NY: Harper.

Judd, C. M., McClelland, G. H., \& Ryan, C. S. (2009). Data analysis: A model comparison approach., $2^{\text {nd }}$ ed. New York, NY, US: Routledge/Taylor \& Francis Group.Kahneman, D., \& Frederick, S. (2005). A model of heuristic judgment. K. J. Holyoak \& R. G. Morrison (Eds.), The Cambridge handbook of thinking and reasoning (pp. 267-293). New York, NY: Cambridge University Press.

Kahneman, D., Diener, E., \& Schwarz, N. (Eds.). (1999). Well-being: Foundations of hedonic psychology. Russell Sage Foundation.

Lakoff, G., \& Johnson, M. (1999). Philosophy in the flesh: The embodied mind and its challenge to western thought. New York, NY: Basic Books.

Lambdin, C., \& Shaffer, V. A. (2009). Are within-subjects designs transparent? Judgment and Decision Making, 4, 554-566.

Mason, W. \& Suri, S. (2012). Conducting behavioral research on Amazon's Mechanical Turk. Behavior Research Methods, 44, 1-23.

Montello, D. R., Fabrikant, S. I., Ruocco, M., \& Middleton, R. S. (2003). Testing the first law of cognitive geography on point-display spatializations. In Spatial information theory. Foundations of geographic information science (pp. 316-331). Springer Berlin Heidelberg.

National Association of Realtors. (2016). Home buyer and seller generational trends. Retrieved from http://www.realtor.org/reports/home-buyer-and-seller-generationaltrends

Paolacci, G., Chandler, J., \& Ipeirotis, P. G. (2010). Running experiments on Amazon Mechanical Turk. Judgment and Decision Making, 5, 411-419.

Parducci, A. (1963). Range-frequency compromise in judgment. Psychological Monographs, 77, 1-50. 
Parducci, A. (1965). Category judgment: a range-frequency model. Psychological Review, 72, 407.

Peters, E., Västfjäll, D., Gärling, T., \& Slovic, P. (2006). Affect and decision making: A "hot" topic. Journal of Behavioral Decision Making, 19, 79-85.

Schelling, T. C. (1969). Models of segregation. The American Economic Review, 59, 488-493.

Schwarz, N., \& Bless, H. (1992). Constructing reality and its alternatives: An inclusion/exclusion model of assimilation and contrast effects in social judgment. In $\mathrm{H}$. Martin \& A. Tesser (Eds.), The construction of social judgment (pp. 217-245). Hillsdale, NJ: Erlbaum.

Schwarz, N., \& Bless, H. (2007). Mental construal processes: The inclusion/exclusion model. In D. A. Stapel \& J. Suls (Eds.), Assimilation and contrast in social psychology (pp. 119-142). Philadelphia: Psychology Press.

Slovic, P., Finucane, M. L., Peters, E., \& MacGregor, D. G. (2007). The affect heuristic. European Journal of Operational Research, 177, 1333-1352.

Suls, J. and Wheeler, L. (2000). A selective history of classic and neo-social comparison theory. In J. Suls and L. Wheeler (Eds.), Handbook of social comparison: Theory and research. New York: Kluwer Academic.

Suls, J., \& Wheeler, L. (2007). Psychological magnetism: A brief history of assimilation and contrast in psychology. In D. A. Stapel \& J. Suls (Eds.), Assimilation and contrast in social psychology (pp. 9-44). New York: Psychology Press.

Tversky, A., \& Kahneman, D. (1983). Extensional versus intuitive reasoning: The conjunction fallacy in probability judgment. Psychological Review, 90, 293-315.

Wertheimer, M. (1923). Untersuchungen zur Lehre von der Gestalt. II. Psychologische Forschung, 4, 301-350. 
Wyer, R., Clore, G. L., \& Isbell, L. (1999). Affect and information processing. In M. P. Zanna (Ed.), Advances in experimental social psychology (Vol. 31, pp. 1-77). New York: Academic Press. 